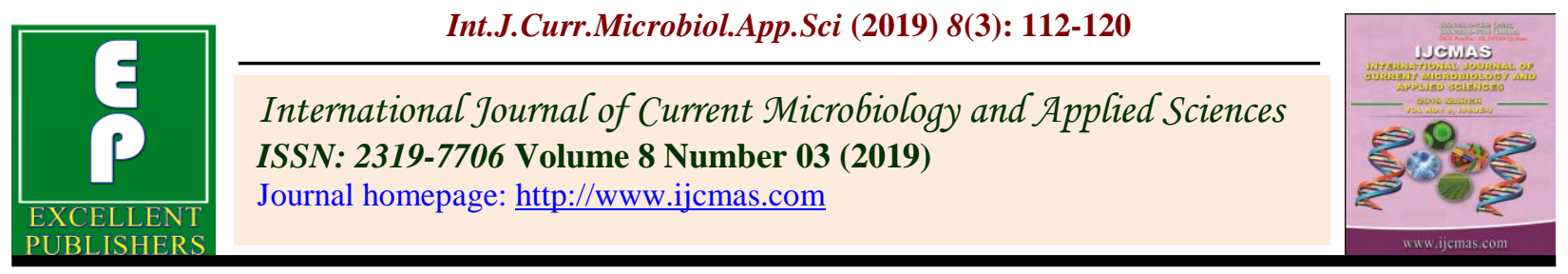

Case Study

\title{
Case Studies on the Utilization of Geospatial Technology for Sustainable Agriculture
}

\author{
K. Ravi Chandra Charyulu ${ }^{1}$ *, Ganjikunta Sambasiva Rao $^{2}$, \\ Mukkala Pradeep Kumar ${ }^{1}$ and Madineni Lokesh ${ }^{1}$
}
${ }^{1}$ Department of Applied Engineering, ${ }^{2}$ Department of Civil Engineering, Vignan's Foundation for Science, Technology and Research (VFSTR), Vadlamudi-522213, India

*Corresponding author

\section{A B S T R A C T}

\begin{tabular}{|l|}
\hline Ke y w o r d s \\
Geospatial \\
technology, \\
$\begin{array}{l}\text { Agriculture, SARD, } \\
\text { Remote sensing }\end{array}$ \\
\hline Article Info \\
\hline $\begin{array}{l}\text { Accepted: } \\
\text { 04 February } 2019 \\
\text { Available Online: } \\
\text { 10 March } 2019\end{array}$ \\
\hline
\end{tabular}

\begin{abstract}
Agricultural sustainability is the highest priority in developed and developing countries. This study aims in discussing the impacts and applications of geospatial information technology in agriculture and allied branches. These advanced technologies offer multi-scale benefits and they can be used to create and synthesize new low-cost information and documents. Quick data sources and integration methods provide diagnostic error detection and feedback to provide accurate input data for various agricultural production methods and pollution from diffuse sources, and prepare maps and charts that meet the specific needs. Geospatial technology provides direct information or production indicators (cultivated area and yield). Agricultural parameters such as soil moisture, soil type, cultivation stage, are essential for effective agricultural monitoring. Removing masks can be derived from multifunctional images. Cloaking is an essential requirement for satellite remote sensing for forecasting/estimating crops, useful for the transfer of precision farming. It involves the use of the allocation and management of spatial assets in order to distribute the time and money available, where it is most needed, and will provide the greatest return to the farmers.
\end{abstract}

\section{Introduction}

Sustainable farming practice and rural development (SARD) has the potential to reduce hunger and poverty, while preserving the ecosystems that poor rural populations rely on livelihoods (International Institute for Sustainable Development, 2010). Study due to lack of rural areas have problems related to the sustainability of agriculture, natural resource management, business diversification, agricultural efficiency and long-term growth and planning (Ohio
Geospatial Program: Agriculture and Natural Resources, 2003). Sustainable agricultural productivity in the 1970s was not an important issue as food resources do not seem to be at risk. Attention has been drawn to food production to overcome immediate food shortages. However, intensive agriculture on the environment, such as soil erosion, salinization, soil and surface water pollution and biodiversity loss occurred because the land that was not used in accordance with its sustainable potential, which ultimately led to concerns on the problems of agricultural 
production at world level and at national level (FAO, 1995). Sustainable agriculture involves effective, efficient environmental, economic and social management. Furthermore, it implies the dynamic interaction between technology, environment and society. Agricultural task management systems research in the 21st century is to make the transition to sustainable agricultural development, including concept of functional sustainability of agricultural research policies, programs and projects (Parris and Kates, 2003; Clark and Dickson, 2003). This problem can be solved using geospatial information technology (Wikipedia, 2010).

GIS has proven to be an effective and effective tool for spatial analysis and management of natural resources. GIS is a branch dedicated to geospatial information technology that allows to store, manage and analyze geographical data. Remote sensing data collection systems, such as aerial photographs and satellites, provide periodic land use, land cover and other thematic information (Deichmann and Wood, 2001). GIS, Global Positioning System (GPS) and image processing software system that manages RS data consists of basic components of geo-spatial information technology. These geospatial technologies are the basis for precise agriculture, which represents a paradigm shift in agriculture (Mandal and Ghosh, 2000). Geotechnical decision-making systems are based on the variability of crops, soil and other related factors. A study reported by Bobade et al., (2010) Seoni District, Madhya Pradesh, India, based on the survey data of the land, which uses GIS technology was carried out land assessment of agricultural planning.

The geographical area has been compiled and interpreted in relation to the adequacy of land use and fertility assessment in the Seoni district. The records of the geographic information system were created using fertility maps and territorial suitability. The suitability map for each agricultural land was developed by combining the climatic and soil conditions of each crop in the study area using precise farming approaches. They recognized that the use of geospatial technology is very important for the planning and decision-making of agricultural production. At present, geospatial information technologies are becoming increasingly important in the decision-making process related to spatial planning. GIS, together with satellite data, provides decision makers with a unique panoramic view that allows land managers to improve the management of natural resources. The use of georeferenced information is a dialogue that connects local knowledge and science and national development strategies. An advantage of geospatial data is the ability to increase the accuracy of data collection and analysis (Blaschke, 1999). These technologies have been successfully used to successfully manage land resources in most developed industrialized countries.

The increasing availability of remote sensing images, which is periodically obtained with satellite sensors in the same geographic area, makes the development of monitoring systems able to automatically generate and regularly update the coverage map soft hear territory very interesting (Bruzzone et al., 2002). Naesset (1997) has reported the use of GIS technology as a decision support tool for conserving forest biodiversity in Norway. A better assessment of changes to land cover through digital analysis of a remote satellite data sensor helps decision- makers to develop effective land use management plans (Gordon, 1980; Milington et al., 1986; Franchek and Biggam, 1992). South African natural resources and agricultural policy issues are largely based on information provided by the scientific community. This 
information is included in the data of various branches of the social sciences in order to obtain political decisions. Remote sensing has been used as a tool for monitoring natural resources and agricultural uses in South Africa. It is used in a policy-oriented approach to provide information that influences development decisions (Petja et al., 2004).

\section{Objectives - following are the objectives of this study}

1. To discuss the Present Scenario of Remote Sensing in Agriculture

2. To converse about Crop Acreage and Production Estimation,

3. The exchange view on Geographical Information System (GIS) in Agriculture, Precision farming and its Opportunities \&Challenges

\section{Materials and Methods}

This is a descriptive study based on secondary data. To draw conclusions, various research journals, books, websites and various reports have been studied relating to the current scenario of remote sensing in agriculture, evaluation of harvesting and production, agriculture of the geographical information system (GIS), precise agriculture and capacity and challenges. Geospatial technologies include widely mapping and sensing, remote sensing, photogrammetry, cartography, global positioning systems (GPS) and geographic information systems (GIS). Thanks to its unique ability to obtain spatial information, georeferenced integration and analysis, this technology has recently been recognized as an effective tool for planning, management and decision both locally and globally.

\section{Geospatial technologies}

Geospatial technology has emerged in various sectors of society, as well as in the private sphere in India. The main sectors that use geospatial technology in India are agriculture, telecommunications, oil and gas, environmental management, forestry, public safety, infrastructure, logistics, etc. As industry players become aware of the longterm utility and profitability of geospatial tools and technologies, the geospatial industry will make progress, leaps and bounds over the next few years. Well-formulated policy mechanisms, government support and everincreasing domestic demand will go along way in promoting geospatial technology in India and will contribute decisively to effective governance and development planning.

The FICCI geospatial technology task force aims to integrate the use of geospatial technology into various industries and applications in India. The following objectives are broadly outlined:

- Raise public awareness and promote the use of geospatial technology in order to obtain better information and decisions

- Identify successful case studies and geospatial methods for replication

- collaborate with the government at all possible levels to identify and address policy issues in the sector

- Efforts to recognize this topic as one of the main opportunities for higher education and careers

- Promote a common platform for all stakeholders to strengthen the feedback mechanism between government, industry and academia

- Evaluate and improve the level of involvement in various sectors of the economy

Increase capacity

\section{Results and Discussion}

This document deals with various factual data related to the current scenario of remote sensing in agriculture, evaluation of 
harvesting and production, geographic information system (GIS) in agriculture, precise agriculture and its capabilities and challenges.

\section{Remote sensing in agriculture: current scenario}

Remote sensing techniques are important crops in the identification of rural areas and estimates of production, disease and stress tests, soil and water characterization, as well as providing the necessary resources for the following purposes: soil and water resources development plans, further mapping crops and the restoration of empty land increase irrigation potential using cartographic groundwater types; crop yields and weather models, integrated pest management, command area management, water basin management, agro-meteorological services, precision agriculture and so on. Development of applications in agriculture has become at a level where these resources are used for policy decisions related to food security, poverty reduction and sustainable development of the country. Decision on stocks of food grains can be based on the harvest harvest and production forecasts, but the underground prospects map is the main source of information, providing drinking water areas and other rain and disadvantaged needs. A national desert mapping, land use, land and soil cover helped to expand and intensify agricultural activities, as well as to identify class soil capacity and suitability crop indices.

\section{Agricultural area and production estimate}

India cosmic observation data in the rural area of the evaluation production and the forecast was tested in the early 1980 s areas of wheat, rice and peanuts chosen. The preliminary study promising results and favor led to the attempt to assess the national wheat area, using the data Lands at MSS Haryana and Punjab $1985-86^{\text {th }}$ The results were encouraging, and the project, namely "Apsegums plant production and evaluation "(CAPE), was launched in the case of wheat, rice, peanuts and sorghum selected in the main growing countries / areas. As the monsoon season there are concerns about the availability of optical data, the active use of sensor data, such as RADARSAT SAR has been used kharif rice 12 areas of Karnataka. Microwave oven data with all possible weather conditions, have shown that the rice crop can discriminate better than $90 \%$ accuracy, which can help determine the number of early anticipation.

In addition to being used for a single date, high-resolution satellite data to provide a surface of a district level calculus space under the multi-year CAPS WiFS data (high resolution and high sensitivity) are used to explore the possibility of forecasting at the national. The procedure uses a national sampling and segmenting the coarse sample networks to carry out a series of projections, as well as increasing seasonal cultural differences in a multi- WiFS data set. A complete software package name, CAPEWORKS / CAPEMAN, which allows a complete analysis, ends with the production of statistics, and remote sensing techniques have been used to evaluate horticultural crops, for example, the Indian plant Horticultural Research Institute, a joint venture. Venture was successfully performed in the mango evaluation and plantings of human resource bananas and the district of Krishna district of AP thiruchirapalli of Tamil Nadu with $94 \%$ accuracy and mapping is done to help different users and cooperative, accurate evaluation of the area It also performs the cadastral level, which allows the government to identify beneficiaries (farmers) who do not pay taxes. Northern region Nasik District, Maharashtra area onion region for evaluation, 
given the smaller size of the field, a kind of page structure, continuous cultivation and mixing range with other cultures, results $75 \%$ accuracy. From the experience gained in the implementation of the CAPE project, as well as to meet the timeliness requirement, the accuracy and coverage of the crops has developed a concept of agriculture output integrated forecast to use space, agrometeorology and terrestrial observations (FASAL). The Center for the prognostication of state crops is established by the Department of Agriculture and Cooperation, Govt. from India to complete the project. (As remote sensing, climatic and field observations provide additional information and to obtain collection forecasts FASAL offers an approach that integrates these three types of impulse observations to prepare forecasts for desired coverage, accuracy and timeliness). The FASAL concept thus strengthens the existing assessments of the crops in the first season through econometric and meteorological techniques that use medium-term distance assessments that can be integrated by the analysis of multidimensional data based on time. In the next part of the growing season, the direct impact of remote sensing is available in the form of field estimation and extraction. However, adding more rural information and weather information in this case would increase the accuracy of the forecast. India also plans some exclusive satellites to provide agricultural data.

\section{Geographic information system (GIS)}

Agricultural land and water resources and the integration of restriction / ecological identification problems at micro level will help to determine the location of specific solutions, the effective use of information based on remote sensing, using geographic information systems, together with other socio-data cheap. This is done by looking at the resources in different quantities, using traditional methods and remote sensing, collecting security information, such as slope, topography, etc., preparing the deck of Resource cards (hydro geomorphology, soil, landuse/ coverage, surface water/drainage/ water, etc.). and action plan, the preparation of maps that are listed in the site specific recommendations for agriculture, underground catering, fuels and forage development and management, as well as conservation / regeneration and afforestation. In one of the NRSA experiments using GIS techniques he created a sustainable action plan Machkund upper part of the river, located in the Visakhapatnam district, Andhra Pradesh tribal areas. GRAM ++ is locally developed geographic information system (GIS), software package for storing geographical information, analysis and recovery, which is essential for a local activity level planning (GRAM ++ geographically determined package area management), the local planning tool for natural resources of the data management system, Department of Science and Technology, Government of India. The package has been used in various applications such as waterfalls management, waste reclamation, soil capacity analysis, soil erosion assessment, energy planning, placement/ distribution object and hazardous research zone subdivision. These applications have been made and the functionality has been verified by the Karnataka State Science and Technology Council of Bangalore; Information technology design Endeavor, Bangalore, National Atlas and Thematic cartography organization, Calcutta, the National Agency for Water Development, New Delhi and many other universities and research and development institutions. According to NNRMS, Space Departmental Policymakers is being developed for Natural Resources Information System (NRI) to ensure optimal use of natural information 
resources. This information system will allow to update existing information on natural resources and to integrate with socioeconomic data. GIS is the NRIS core for storing, retrieving, integrating and analyzing data. It will also be linked to other existing information systems at the district/national level in order to provide an effective and efficient means of resource management. NNRMS (2000) has prepared a document on the design and the node standards to be adopted in all NRI topics, such as land, land use, water, geomorphology, socio-economic data, infrastructure and soon. Thus, the potential of GIS is very large to improve the management of resources in order to sustainably improve productivity in an ecological way. It includes a large database collection and formatting, in collaboration with the line departments / authorities in order to get the maximum benefit from these technologies.

\section{Precise cultivation}

The modernization of agriculture is a new concept in modern agriculture. This is a micromanagement system to obtain better decisions on agricultural and territorial management deriving from the use of information provided by geospatial technology. In other words, it is a "digital farming", which includes a very large scale farm mapping, complete databases on the resources needed, obtained through space materials and field observations, and a detailed work plan, at the to maximize yield and reduce raw material costs through a decision support system.

The exact agricultural database usually includes:

Characteristics of plants, such as yield, crop health, nutritional requirements, etc.

Detailed soil layer with physical and chemical properties, depth, consistency, nutritional status, salinity and toxicity, soil temperature, potential for productivity, etc.

Microclimatic data (seasonal and daily) on the temperature of the buildings, wind direction and speed, humidity, etc.

Surface and underwater drainage conditions; Irrigation equipment, water availability and other interesting planning functions

A high precision global positioning differential system (GPS) introduction, there are opportunities to automate business activities such as management, planting, fertilizer use, pesticides / herbicides spraying, irrigation, harvesting and other mechanized cultural activities. High-resolution digital models (DEM) can also create a database component that provides an adequate description of the topography to support models of soil moisture and decisional fertility. Precise agriculture provides micromanagement concepts that include the ability to properly manage each field of action in each position field where it is technically and economically feasible to perform at this level. The concept of precise agriculture in developed countries has grown very rapidly due to large farms and completely mechanized agricultural activities. With modern technology and the highest resolution multispectral sensor data for developing countries, including India, it is possible to take an accurate high agricultural value of cultivation / commercial / fruit / flowers / vegetables etc. Remote sensing methods and GIS in the management of agricultural resources is growing rapidly due to spatial satellites observed improved spatial, spectral, time and radiometric resolution. Many traditional approaches to processing multimedia information for optimal solutions are computerized using GIS utilities. In view of the satellite, computer and communication technology development in India are available 
following options and the problems associated with remote sensing and GIS in precision farming technology.

The following features should be addressed in the application of these technologies.

Priority definition of metropolitan macro / areas for the implementation of water basin projects and impact assessment at national, state, district, taluk and hobli levels.

Prediction of pests and diseases epidemics based on soil water status and herbal stress in crops such as pad locks, wheat, sugar cane, cotton, red pepper and peas, etc.

Start the creation of a decision support system for the precise management of resources at farm level, at least in the commercial / fruit / flower cultures.

Use of SAR data for the identification of harvested crops and procedures for modeling inverse foliage models for identification and foreground extraction.

Land mapping on a cadastral scale using high resolution spatial, spectral and radiometric resolutions.

Quantitative determination of loss of soil.

Determination of water registration due to increasing groundwater table.

Soil sliced from black earth salt and sandy regions.

Determination and mapping of soil moisture using microwave/ optical/ thermal remote sensing methods at the depth of the surface and root area.

Calculation of the surface temperature of the earth by means of remote thermal and microwave control methods.

Studies on hyper-superficial soil to determine the quantitative relationship between spectral reflection and soil properties.

Development of digital techniques for various applications using GIS methods. For example, soil suitability for crops, soil capacity classification and soil irrigation estimation, etc.

Preparation for the use of hyper-spectrum data to understand plant processes and develop spectral response models for stress assessment.

Improved productivity models by integrating biophysical simulation and regional crop models. Challenges. The use of methods of development, GIS and precision agriculture in the management of agricultural resources is growing rapidly thanks to the improvement of the spatial sciences supported by information and communication technologies.

The following problems should be addressed when these technologies are applied.

Crop identification and area evaluation and cultivation of temporary crops grown on fragmented farms, especially during the karate season

Drought / flood forecasts.

Soil stress caused by nutrients, pests and diseases and their effect on yields.

Automation of territorial assessment procedures for various applications using GIS methods.

Information on the superficial horizons of the ground.

Extension of the precision agriculture database to the size of smaller farms and / or different crops / growing systems.

Development of decision support systems for the management of biotic and abiotic stress at farm level.

Models of more precise crops

Evaluation of water depth in tanks and assessment of ground water quality.

Better than $1 \mathrm{~m}$ plan of aquifer development outline at the micro level.

The use of remote sensing and precision cultivation technologies in intercultural / multiple situations.

To identify ways and means to reduce RS, GIS and precision farming technology costs, as well as data collection, interpretation and distribution of time differences so that they can be widely used. An example of success in this direction is the handshake radiometer developed by optomech engineers in Hyderabad, in collaboration with the Space 
Application Center, ISRO in Ahmedabad, to standardize the spectrum signatures to request $\mathrm{RS}$ data transfer.

Conclusive evidence to demonstrate the usefulness of this technology and economic profitability, in order to mobilize support for research and development.

Development of human resources to accelerate the widespread use of unexplained and cutting-edge technologies with enormous scope and potential.

In conclusion, curious about exact cultivation (PF) and its implementation have involved the gap between technological capabilities and scientific knowledge of the relationship between input and output. Agriculture, a dynamic system governed by a number of biotic and abiotic factors, must be preserved because it is a key member of the Indian economy. Even if we are self-sufficient rain production, there are several shady areas that should be improved to achieve every green revolution. A transformation of low-yield food production system for high productivity through agro technology (mainly manufacturing), biotechnology (related productivity) convergence with space technology (RS and GIS). Launch of satellites such as IKONOS-II Quick Bird 2, MES and the planned Earth observation mission, namely Resourcesat-1 Cartosat-1 and Cartosat-2 Orbriew-3, SPOT-5 and Advance Land Observation Satellite (ALOS) can make you can get detailed and accurate information about the land and water resources. To facilitate the acquisition of crop information during the Kharif season, India has proposed to launch a special microwave missions namely, Radar Imaging Satellite (Laughter) C-band SAR. High-resolution DEM generation is another important requirement for basin development. Remote data acquisition data, GIS techniques and precision agriculture information databases to the translations chemes implemented in the field at the level of technology and learning in practice from the actual beneficiaries, is still technology a greater challenge.

\section{References}

ARC-ISCW. (2008). Natural Resource Databases. ARC-Institute for Soil, Climate and Water, Pretoria. Blaschke,

T. (1999). Sustainability with GIS towards a proactive nature conservation approach. Retrieved July 27, 2010.

Bairagi, G.D., Hassan, Z., (2002), Wheat Crop Production Estimation Using Satellite Data. Journal of the Indian Society of Remote Sensing, 30(4), pp 213-219.

Bingfng, W., Chenglin L., (2000), Crop Growth Monitor System with Coupling of AVHRR and VGT Data, vegetation 2000, conference, Lake Maggiore - Italy.

Gaikwad, B. P.,, M. S., Raja, P., Gaikwad, S. S., Anantwar, S. G. Maji, A. K. (2010). A GIS-based land use suitability assessment in Seoni district, Madhya Pradesh, India. International Society for Tropical Ecology, 51(1), 41-54.

Burrough, P.A., McDonnell, R.A., (1998), Principles of geographic information systems. Oxford University Press, Oxford, UK, pp 10-16.

Bruzzone, L., Cossu, R., and Vernazza, G. (2002). Combining parametric and nonparametric algorithms for a partially unsupervised classification of multitemporal remote sensing images. Information Fusion, 3, 289-297

Clark, W. C., and Dickson, N. M. (2003). Sustainability science: The emerging research program. Proceedings of the National Academy of Sciences, 100, 8059-8061.

Deichmann, U., and Wood, S. (2001). GIS, GPS, and Remote Sensing, Brief 7 of 9. 2020 Focus 7 (Appropriate Technology for Sustainable Food). International Food Policy Research Institute (IFPRI). Retrieved July 26, 2010, fromhttp://www.ifpri.org/2020/focus/focu s07/focus07_07.htm

Enviro GIS, and ARC. (2007). Limpopo Agricultural Development Strategy. 
Enviro GIS Pty Ltd, Pretoria. Enviro GIS. (2009). Crop Suitability, Crop Rotation Scheduling and Land Use Planning: Nebo Agricultural Hub. Enviro GIS Pty Ltd, Pretoria.

FICCI. Agriculture overview; (2012). Accessed 26.5.2012. Available: http://www.ficcib2b.com/sector overview- pdf/Sectoragri.pdf.

FAO. (1995). World Agriculture Towards 2010. In N. N. Alexandratos (Ed.), FAO Study. Rome, Italy: FAO.

Fassio, A., Giupponi, C., Hiederer, R., and Simota, C. (2005). A decision support tool for simulating the effects of alternative policies affecting water resources: an application at the European scale. Journal of Hydrology, 304, 462476.

Franchek, R. J., and Biggam. P. F. (1992). Using USDA Soil Conservation Service County Soils Data with a Geographic Information System: Geographic Information Systems and Mapping Practices and Standards, ASTM STP 1126 (pp. 115-121). In A. I. Johnson, C. B. Pettersson, and J. Fulton (Eds.). Philadelphia: American Society for Testing and Materials.

Gordon, S. (1980). Utilizing Land sat imagery to monitor land use change: A case study in Ohio. Remote Sensing of Environment, 9, 189-196.

Gowrisankar, D. and Adiga, S., (2001), Remote sensing in agricultural applications: An overview. PP: 9-14, In: Proc, The First National Conference on Agro-Informatics (NCAI), INSAIT, Dharwad.
Greater Sekhukhune District Municipality. (2005). The Integrated Development Plan: 2005-2008. Greater Sekhukhune District Municipality, Groblersdal.

International Institute for Sustainable Development. (2010). Sustainable Agriculture and Rural Development (SARD) Initiative. Retrieved July 27, 2010.

Joubert R. Precision farming - suitable for large or small farms. (2012).

Junying, S, Jinliang, H., Jing, C., Lihui, W., (2009), Grain Yield Estimating for Hubei Province Using Remote Sensing DataTake Semilate Rice as an Example, 2009 International Conference on Environmental Science and Information Application Technology, pp 497-500.

Laurila, H., Karjalainen, M., Kleemola, J., Hyyppa, J., (2010), Application of Remote Sensing Technology in crop acreage and yield statistical survey in china Lutz, W., Sanderson, W. and Scherbov, S., 1997, Doubling of world population unlikely. Nature 387, pp. 803805.

Liaghat, S., and Balasundram S.K., (2010), A Review: The Role of Remote Sensing in Precision Agriculture. American Journal of Agricultural and Biological Sciences 5(1): 50-55.

Mackay D. Precision Farming: connecting the pieces. (2012). Accessed 26.6.2012. Available:

http://www.personal.psu.edu/pwl5119/blo gs/bill_lim/assets/Limpisathian,\%20P.\%2 0GI S\%20Paper.pdf.

\section{How to cite this article:}

Ravi Chandra Charyulu, K., Ganjikunta Sambasiva Rao, Mukkala Pradeep Kumar and Madineni Lokesh. 2019. Case Studies on the Utilization of Geospatial Technology for Sustainable Agriculture. Int.J.Curr.Microbiol.App.Sci. 8(03): 112-120. doi: https://doi.org/10.20546/ijcmas.2019.803.016 